\title{
Ruptured Extracranial Vertebral Artery Aneurysm Associated With Neurofibromatosis Type 1
}

\author{
-Case Report-
}

\author{
Hisaya HiRAmatsu, ${ }^{1}$ Shusuke MATSUI, ${ }^{1}$ Shuhei YAmashita, ${ }^{2}$ Mika KamiYa, ${ }^{2}$ \\ Tae YAMASHITA, ${ }^{1}$ Kyo AKAI, ${ }^{1}$ Kenichi WATANABE, ${ }^{3}$ and Hiroki NAMBA ${ }^{1}$
}

Departments of ${ }^{1}$ Neurosurgery and ${ }^{2}$ Radiology, Hamamatsu University School of Medicine, Hamamatsu, Shizuoka;

${ }^{3}$ Department of Radiology, Okazaki City Hospital, Okazaki, Aichi

\begin{abstract}
A 31-year-old man presented with a ruptured right extracranial vertebral artery aneurysm associated with neurofibromatosis type 1 , manifesting as acute onset of right neck and shoulder pain, and right supraclavicular mass. Three-dimensional computed tomography angiography showed a large aneurysm involving the right extracranial vertebral artery associated with a pseudoaneurysm. The aneurysm was successfully treated by transarterial endovascular trapping with detachable coils. Extracranial vertebral artery aneurysm is rare, but the mortality of ruptured cases is extremely high, so early diagnosis and early treatment are important. The present case shows that endovascular treatment was very effective.
\end{abstract}

Key words: neurofibromatosis type 1, vertebral artery, aneurysm, endovascular treatment

\section{Introduction}

Vascular abnormalities associated with neurofibromatosis type 1 (NF1) are mainly characterized by arterial stenosis, occlusion, and rupture, but may also be associated with aneurysmal or fistulous formation of the large and medium arteries. The frequency of vascular lesions in NF1 patients is hard to define because screening studies are not routinely performed, but the prevalence of vascular lesions in large series is $0.4 \%$ to $6.4 \% .^{3,4,11,14)}$ Renal artery lesions are most common (41\%) and are more often stenotic than aneurysmal, but carotid artery, vertebral artery (VA), and cerebral artery aneurysms, reported in 46 patients, occur in the third decade of life and are more common in women. The renal artery is most frequently involved, resulting in renovascular hypertension. ${ }^{14,20)}$ However, extracranial VA aneurysm is rarely associated with neurofibromatosis. . $^{1,2,5,6,8-10,12,13,15-20)}$

We report a case of ruptured extracranial VA aneurysm in a patient with NF1 treated successfully by endovascular embolization.

\section{Case Report}

A 31-year-old man developed right neck and shoulder pain without any traumatic events. He also noticed a large mass on the right supraclavicular region. He was treated at a nearby hospital with drainage tube placement, and trans-

Received April 12, 2011;

Accepted September 12, 2011 ferred to our hospital 10 hours later because of continuous bleeding from the drainage. On admission, his blood pressure was $120 / 73 \mathrm{mmHg}$, and hemoglobin level was 12.1 $\mathrm{g} / \mathrm{dl}$ but fell to $8.4 \mathrm{~g} / \mathrm{dl}$ in 2 hours. Physical examination found a large pulsatile supraclavicular mass, and dysesthesia in the peripheral portion of the right upper limb. NF1 was diagnosed based on multiple fibromas and cafe-au-lait spots on his chest and back. Family history found that his father also had NF1.

Computed tomography (CT) showed a massive right supraclavicular hematoma and three-dimensional CT (3D-

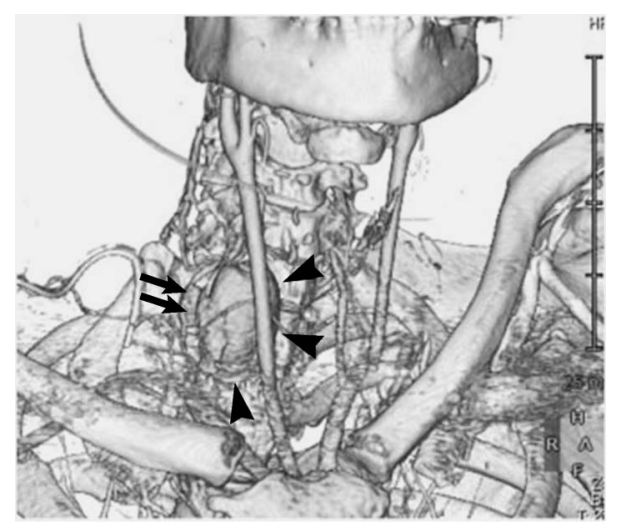

Fig. 1 Three-dimensional computed tomography angiogram showing a right vertebral artery fusiform aneurysm (arrows) and a pseudoaneurysm (arrowheads). 

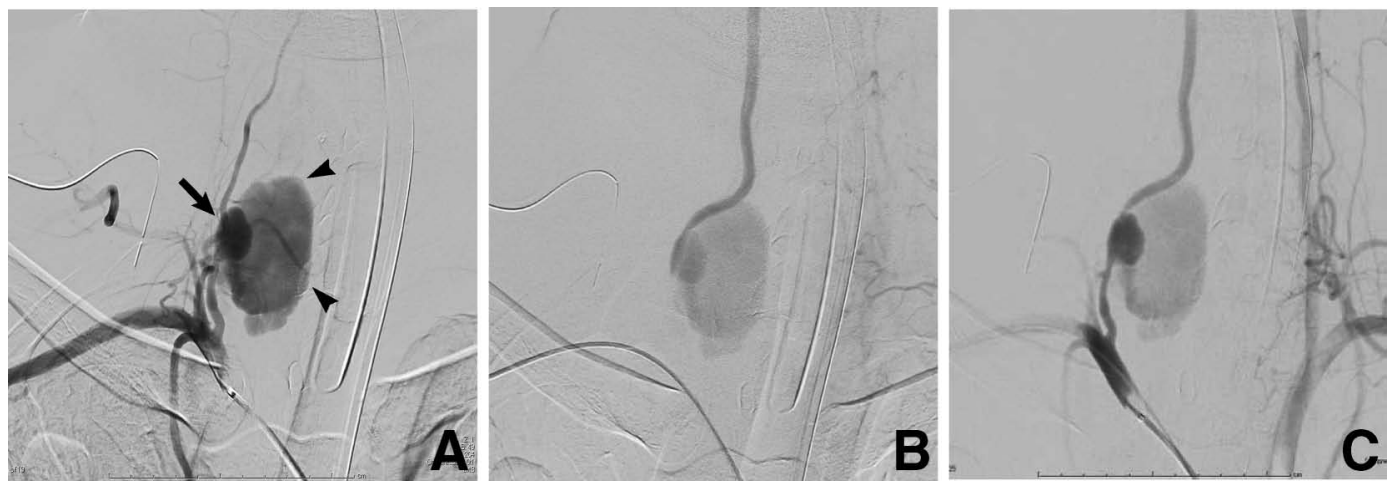

Fig. 2 A: Right subclavian artery angiogram showing a right vertebral artery true aneurysm (arrow) and a pseudoaneurysm (arrowheads), but the distal vertebral artery was not visualized. B: Left subclavian artery angiogram showing the right vertebral artery retrogradely as well as the true aneurysm and pseudoaneurysm. C: Simultaneous angiogram of the right and left subclavian arteries revealing a global image of the right vertebral artery and aneurysm.

CT) angiography demonstrated a large true aneurysm involving the right extracranial VA with the pseudoaneurysm formation (Fig. 1). Cerebral angiography was then started within 3 hours. Right subclavian artery angiography showed a right VA true aneurysm with the pseudoaneurysm. The right distal VA was not visualized (Fig. 2A). Left subclavian artery angiography showed the right distal VA was filled retrogradely as well as the VA true aneurysm with pseudoaneurysm (Fig. 2B). Angiography confirmed the findings of 3D-CT angiography, and suggested fragility of the VA wall which was involved by the aneurysm.

Since angiography had identified problems with the VA wall, this aneurysm had high risk for rupture during embolization. Therefore, endovascular trapping was preferred to intra-aneurysmal obliteration. A 6-Fr OPTIMO balloon guiding catheter (Tokai Medical Products, Kasugai, Aichi) was introduced into the right subclavian artery via the right femoral artery for flow control, and a 4-Fr diagnostic catheter into the left subclavian artery via the right brachial artery. Simultaneous right and left subclavian artery angiography revealed a global image of the right VA, true aneurysm, and pseudoaneurysm (Fig. 2C). Consequently, we could understand the angioarchitecture of the normal VA and aneurysm. A microcatheter was then introduced into the distal VA through the proximal VA bypassing the orifice of the aneurysm. Endovascular trapping with detachable coils (GDC18 Soft \&18 Standard [Boston Scientific, Natick, Massachusetts, USA], DETACH-18 [Cook Medical Technologies, Bloomington, Indiana, USA], and Tornado fibered coils [Cook Medical Technologies]) was subsequently performed from the distal VA to the proximal VA including the true aneurysm with flow control on standby (Fig. 3A).

No aneurysm was visualized by postoperative right subclavian artery angiography (Fig. 3B) or retrogradely by left subclavian artery angiography. The whole endovascular procedure took about 2 hours. After embolization, his blood pressure and hemoglobin level became stable. Dysesthesia of his upper limb was considered to be due to C6 radiculopathy caused by compression by the massive
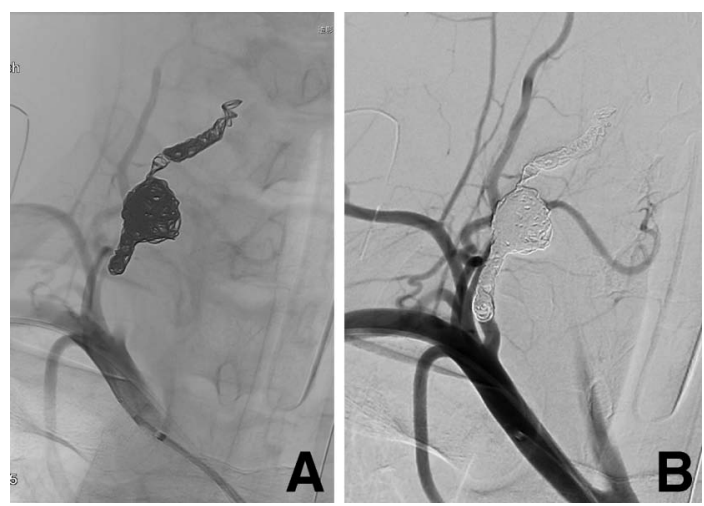

Fig. 3 Postoperative right subclavian artery angiograms showing successful embolization of the aneurysm (A) and no aneurysm and proximal vertebral artery (B). A: digital angiogram, B: digital subtraction angiogram.

hematoma, and gradually improved with absorption of the hematoma. Systemic 3D-CT angiography showed no aneurysm involving the extracranial VA and other arteries.

\section{Discussion}

A total of 18 cases of extracranial VA aneurysms associated with NF1 have been described: 9 ruptured cases (including the present case) and 9 unruptured cases (Tables 1 and 2). All 9 ruptured cases manifested as local neck pain at first (Table 1). Hypotension occurred subsequently in most cases, followed by hemorrhagic shock if the patients were not appropriately treated. Once the bleeding extended into the thoracic cavity, the outcome was serious; 2 patients died and 2 were severely disabled (vegetative state) because of hypoxic brain damage. ${ }^{1,12)}$ Treatment for stopping the bleeding is essential as soon as possible in patients with ruptured aneurysm. Endovascular treatment is considered to be the treatment of choice, and was performed in 7 of the 9 ruptured cases. 
Table 1 Ruptured extracranial vertebral artery aneurysms in patients with neurofibromatosis type 1

\begin{tabular}{|c|c|c|c|c|c|}
\hline $\begin{array}{l}\text { Case } \\
\text { No. }\end{array}$ & Author (Year) & $\begin{array}{l}\text { Age (yrs)/ } \\
\text { Sex }\end{array}$ & Symptoms & Treatment & Outcome \\
\hline 1 & Negoro et al. (1990) $)^{13)}$ & $47 / \mathrm{M}$ & pain, cervical mass & endovascular (balloon) & GR \\
\hline 2 & Horsley et al. $(1997)^{10)}$ & $56 / \mathrm{F}$ & pain, arm paresthesia, dyspnea & endovascular (coil) & GR \\
\hline 3 & Ushikoshi et al. (1999) ${ }^{20)}$ & $40 / \mathrm{F}$ & back pain, hematoma & endovascular (balloon) & GR \\
\hline 4 & Miyazaki et al. (2004) ${ }^{12)}$ & $52 / \mathrm{F}$ & $\begin{array}{l}\text { pain, hypotension, } \\
\text { consciousness disturbance }\end{array}$ & $\begin{array}{l}\text { endovascular (balloon), } \\
\text { direct surgery }\end{array}$ & $\mathrm{D}$ \\
\hline 5 & Arai et al. $(2007)^{1)}$ & $38 / \mathrm{M}$ & chest pain, dizziness, vomiting & untreated & $\mathrm{D}$ \\
\hline 6 & Hieda et al. $(2007)^{5)}$ & $36 / \mathrm{F}$ & back pain, dyspnea, hypotension & endovascular (coil, NBCA) & VS \\
\hline 7 & Oderich et al. $(2007)^{14)}$ & $43 / \mathrm{F}$ & brachial plexopathy, hematoma & direct surgery & GR \\
\hline 8 & Higa et al. $(2010)^{6)}$ & $60 / \mathrm{F}$ & $\begin{array}{l}\text { neck hematoma, stridor, } \\
\text { respiratory failure }\end{array}$ & endovascular (coil) & VS \\
\hline 9 & Present case & $40 / \mathrm{M}$ & neck pain, hematoma & endovascular (coil) & GR \\
\hline
\end{tabular}

D: dead, F: female, GR: good recovery, M: male, NBCA: N-butyl-2-cyanoacrylate, VS: vegetative state.

Table 2 Unruptured extracranial vertebral artery aneurysms in patients with neurofibromatosis type 1

\begin{tabular}{|c|c|c|c|c|c|}
\hline $\begin{array}{l}\text { Case } \\
\text { No. }\end{array}$ & Author (Year) & $\begin{array}{l}\text { Age (yrs)/ } \\
\text { Sex }\end{array}$ & Symptoms & Treatment & Outcome \\
\hline 1 & Schubiger and Yasargil (1978) ${ }^{19)}$ & $50 / \mathrm{M}$ & radiculopathy & direct surgery & GR \\
\hline 2 & Pentecost et al. (1981) ${ }^{16)}$ & $1 / F$ & $\begin{array}{l}\text { limited cervical } \\
\text { movement }\end{array}$ & observation & $\begin{array}{l}\text { SD (intraoperative bleeding } \\
\text { of other aneurysm) }\end{array}$ \\
\hline 3 & Detwiler et al. (1987) ${ }^{2)}$ & $52 / \mathrm{F}$ & pain, radiculopathy & endovascular (balloon) & GR \\
\hline 4 & Schievink and Piepgras $(1991)^{18)}$ & $43 / \mathrm{F}$ & none & observation & no change for 2 yrs \\
\hline 5 & Ohkata et al. (1994) & $48 / \mathrm{F}$ & radiculopathy & direct surgery & GR \\
\hline 6 & Hoffmann et al. (1998) $)^{8)}$ & $59 / \mathrm{M}$ & none & observation & GR \\
\hline 7 & Hiramatsu et al. $(2007)^{7)}$ & $67 / \mathrm{M}$ & dizziness & endovascular (coil) & GR \\
\hline 8 & Peyre et al. $(2007)^{17)}$ & $18 / \mathrm{F}$ & radiculopathy & endovascular (coil, balloon) & GR \\
\hline 9 & Horie et al. (2008) $)^{9)}$ & $30 / \mathrm{F}$ & radiculopathy & endovascular (coil, balloon) & GR \\
\hline
\end{tabular}

F: female, GR: good recovery, M: male, SD: severely disabled.

Radiculopathy was the main symptom in 5 of the 9 patients with unruptured aneurysms, as a result of compression of the nerves by the enlarged VA aneurysm (Table 2). Local bruit heard with a stethoscope was also present. Most aneurysms were the fusiform type, so surgical trapping and removal of the aneurysm, or endovascular trapping with coils and/or detachable balloons were indicated. If only proximal occlusion of the parent artery is performed, the aneurysm may not disappear and will be recanalized by blood flow from the opposite VA and other collateral vessels. ${ }^{7)}$ In fact, a previous case, treated with proximal occlusion with a detachable balloon, developed vertebral arteriovenous fistula in the same region 11 years later. ${ }^{20)}$ Therefore, endovascular trapping of the distal parent artery, aneurysm, and proximal parent artery is supposed to be a better treatment modality. Direct surgery was selected in earlier cases, whereas endovascular treatment was chosen in more recent cases. Endovascular treatment has the advantage of being minimally invasive and with short operation duration, particularly for ruptured aneurysms. ${ }^{7)}$ In our case, simultaneous right and left subclavian artery angiography was useful to understand the angioarchitecture of the normal VA and aneurysm.

Since the outcome for patients with ruptured aneurysms was extremely poor, unruptured aneurysms should be treated before rupture. Systemic 3D-CT angiography is one of the best imaging modalities for screening of aneurysms in patients with NF1, followed by selective angiography for confirmation. Endovascular treatment is not only less invasive but also more effective because it can be started shortly after the diagnostic angiography.

\section{References}

1) Arai K, Sanada J, Kurozumi A, Watanabe T, Matsui O: Spontaneous hemothorax in neurofibromatosis treated with percutaneous embolization. Cardiovasc Intervent Radiol 30: 477-479, 2007

2) Detwiler K, Godersky JC, Gentry L: Pseudoaneurysm of the extracranial vertebral artery-Case report. J Neurosurg 67: 935-939, 1987

3) Friedman JM, Arbiser J, Epstein JA, Gutman DH, Huot SJ, Lin AE, McManus B, Korf BR: Cardiovascular disease in neurofibromatosis 1: report of the NF1 Cardiovascular Task Force. Genet Med 4: 105-111, 2002

4) Hamilton SJ, Friedman JM: Insights into the pathogenesis of neurofibromatosis 1 vasculopathy. Clin Genet 58: 341-344, 2000

5) Hieda M, Toyota N, Kakizawa H, Hirai N, Tachikake T, Yahiro Y, Iwasaki Y, Horiguchi J, Ito K: Endovascular therapy for massive haemothorax caused by ruptured extracranial vertebral artery aneurysm with neurofibromatosis type $1 . \mathrm{Br}$ J Radiol 80: e81-84, 2007 
6) Higa G, Pacanowski JP Jr, Jeck DT, Goshima KR, León LR Jr: Vertebral artery aneurysms and cervical arteriovenous fistulae in patients with neurofibromatosis 1. Vascular 18: $166-177,2010$

7) Hiramatsu H, Negoro M, Hayakawa M, Sadatou A, Irie $K$, Uemura A, Kanno T, Sano K: Extracranial vertebral artery aneurysm associated with neurofibromatosis type 1. A case report. Interventl Neuroradiol 13 Suppl 1: 90-93, 2007

8) Hoffmann KT, Hosten N, Liebig T, Schwarz K, Felix R: Giant aneurysm of the vertebral artery in neurofibromatosis type 1: report of a case and review of the literature. Neuroradiology 40: 245-248, 1998

9) Horie N, Morikawa M, Kitagawa N, Nakamoto M, Nagata I: Successful endovascular occlusion of an aneurysm of the cervical vertebral artery associated with neurofibromatosis1. Acta Neurochir (Wien) 150: 847-848, 2008

10) Horsley M, Taylor TK, Sorby WA: Traction-induced rupture of an extracranial vertebral artery aneurysm associated with neurofibromatosis. A case report. Spine (Phila Pa 1976) 22: 225-227, 1997

11) Lin AE, Birch PH, Korf BR, Tenconi R, Niimura M, Poyhonen M, Armfield Uhas K, Sigorini M, Virdis R, Romano C, Bonioli E, Wolkenstein P, Pivnick EK, Lawrence M, Friedman JM: Cardiovascular malformations and other cardiovascular abnormalities in neurofibromatosis 1 . Am J Med Genet 95: 108-117, 2000

12) Miyazaki T, Ohta F, Daisu M, Hoshii Y: Extracranial vertebral artery aneurysm ruptured into the thoracic cavity with neurofibromatosis type 1: case report. Neurosurgery 54: 1517-1521, 2004

13) Negoro M, Nakaya T, Terashima K, Sugita K: Extracranial vertebral artery aneurysm with neurofibromatosis. Endovascular treatment by detachable balloon. Neuroradiology 31:
533-536, 1990

14) Oderich GS, Sullivan TM, Bower TC, Gloviczki P, Miller DV, Babovic-Vuksanovic D, Macedo TA, Stanson A: Vascular abnormalities in patients with neurofibromatosis syndrome type I: Clinical spectrum, management, and results. J Vasc Surg 46: 475-484, 2007

15) Ohkata N, Ikoda T, Tashiro T, Okamoto K: [A case of multiple extracranial vertebral artery aneurysms associated with neurofibromatosis]. No Shinkei Geka 22: 637-641, 1994 (Japanese)

16) Pentecost M, Stanley P, Takahashi M, Isaacs H Jr: Aneurysm of the aorta and subclavian and vertebral arteries in neurofibromatosis. Am J Dis Child 135: 475-477, 1981

17) Peyre M, Ozanne A, Bhangoo R, Pereira V, Tadié M, Lasjaunias P, Parker F: Pseudotumoral presentation of a cervical extracranial vertebral artery aneurysm in neurofibromatosis type 1: Case report. Neurosurgery 61: E658, 2007

18) Schievink WI, Piepgras DG: Cervical vertebral artery aneurysms and arteriovenous fistulae in neurofibromatosis type 1: Case reports. Neurosurgery 29: 760-765, 1991

19) Schubiger O, Yasargil MG: Extracranial vertebral aneurysm with neurofibromatosis. Neuroradiology 15: 171-173, 1978

20) Ushikoshi S, Goto K, Ueda K, Ogata N, Takeno Y: Vertebral arteriovenous fistula that developed in the same place as a previous ruptured aneurysm: A case report. Surg Neurol 51: 168-173, 1999

Address reprint requests to: Hisaya Hiramatsu, MD, Department of Neurosurgery, Hamamatsu University School of Medicine, 1-20-1 Handayama, Higashi-ku, Hamamatsu 431-3192, Japan.

e-mail: jzt00467@nifty.com 